\title{
0 ponto de vista no documentário
}

////////////////// Gustavo Souza

1. Pós-doutorando no curso de imagem e som da Universidade Federal de São Carlos. Doutor em Ciências da Comunicação pela Escola de Comunicações e Artes da Universidade de São Paulo.

E-mail: gustavo03@uol.com.br 


\section{Resumo}

Diante das controvérsias que há décadas permeiam a teoria do documentário, especialmente em relação à sua definição ou às suas especificidades, qualquer tentativa nessa direção hoje parece situar-se num campo minado. Ciente desse "risco", pretendemos pensar o ponto de vista no documentário, num debate que articula a materialidade da imagem e do som com a subjetividade decorrente da interpretação, recorrendo a estudos de diferentes tradições teóricas complementares nessa tentativa.

\section{Palavras-chave}

Ponto de vista, documentário, senso de orientação.

Abstract Considering the controversy that has for decades permeated the documentary theory, especially in relation to its definition and specificities, any attempt in that direction now seems to be in a minefield. I intend to consider the possibility of a point of view in the documentary in a debate that articulates the materiality of the image and sound with subjectivity regarding the interpretation, using studies from different theoretical traditions in trying.

\section{Keywords}

Point of view, documentary, sense of direction. 


\section{Introdução}

Diante das controvérsias que há décadas permeiam a teoria do documentário, especialmente em relação à definição ou às especificidades dessa modalidade fílmica, qualquer tentativa nessa direção hoje parece situar-se num campo minado. Apesar desse risco, pretendo neste texto pensar a possibilidade de um ponto de vista no documentário ou ponto de vista documental, num debate que articula a materialidade da imagem e do som com a subjetividade decorrente da interpretação.

Antes de destrinchar esse objetivo, é importante estabelecer as bases teóricas que o alicerçam, uma vez que a expressão ponto

2. No argumento de Jacques Aumont, a pintura é precursora da fotografia e do cinema devido ao enquadramento e às diversas opões de luminosidade. Para detalhes sobre a relação entre cinema e pintura, ver os trabalhos de Bazin (1991) e Aumont (2004). No campo literário, a noção de ponto de vista foi trabalhada por autores como James (2003), a partir de uma preocupação em torno de prefácios, e Genette (1995), que vai introduzir

a discussão sobre focalização na literatura. Para uma articulação desse conceito entre o campo literário e o cinema, ver Jost (2002). de vista é de uso corrente no cotidiano, sujeita, portanto, a variadas definições ou interpretações; assim como pelo fato de a discussão em torno do ponto de vista não ser uma exclusividade da teoria do cinema, sendo antecipada, por exemplo, pela pintura e pela literatura. $^{2}$

A partir da necessidade apontada pelo objetivo acima, centro as atenções nos estudos cinematográficos que se preocuparam com o termo em questão. Sendo assim, o ponto de vista no cinema pode ser definido a partir de três perspectivas: primeiramente, o plano e seu respectivo enquadramento, que podem materializar o olhar do personagem, do narrador ou do autor; uma segunda aponta para o vínculo com a narrativa cinematográfica, isto é, quando o primeiro ponto de vista se articula num desenvolvimento 
3. Segundo o argumento de Aumont (1985, p. 133): "Aquilo de que o cinema toma consciência neste momento da sua história é, antes de mais nada, que o encadeamento de pontos de vista de enquadramentos em lugares diferentes produz um desenvolvimento cronológico, uma narrativa cujos modos se vão aperfeiçoar rapidamente [...]; em suma, esse encadeamento induz um ponto de vista narrativo".

4. De acordo com Branigan (1992, p. 44), essa organização abre também a possibilidade para o que não se vê, mas que integra o espaço da narrativa do filme: "[A] lacuna entre a tela e o espaço da história leva a graus e tipos de espaço "impossível”, isto é, o espaço que não pode ser justificado como existindo inteiramente dentro da diegese. O espaço impossível leva

a problemas de percepção de um novo tipo que forçam o espectador a reconsiderar a hipótese prévia sobre o tempo e a causalidade". No original: "[...] a gap between screen and story space leads to degrees and kinds of 'impossible' space; that is, to space which can not be justified as existing wholly within the diegesis. Impossible

space leads to perceptual problems of a new kind that force the spectator to reconsider prior hypotheses about time and causality" (grifo do autor). cronológico, forma-se o ponto de visa narrativo 3 , podendo este, também, operar a partir de diversas instâncias — diretor, narrador, personagem. Essa possibilidade estabelece uma relação entre “a história contada e a narrativa" (AUMONT; MARIE, 2003, p. 237), no sentido atribuído por Genette, em que se ressalta o modo de narrá-la, posteriormente incorporado aos estudos de cinema por Gaudreault e Jost, para quem toda narrativa articula sempre duas temporalidades: "por um lado, aquela da coisa narrada; por outro, a temporalidade da narração propriamente dita” (GAUDREAULT; JOST, 2009, p. 33). A terceira definição se vincula a uma "atitude mental" (AUMONT, 1985, p. 127) em relação a um objeto, a uma pessoa, a um acontecimento, articulando, como frisa Aumont (1985, p. 131, grifo do autor), "uma tentativa de inscrição do sentido nos filmes, tentativa em que o registro do simbólico é mobilizado". Em outras palavras, esse ponto de vista promove o embate entre as esferas da narração e da representação, num fluxo contínuo em que se estabelecem o tempo e o espaço fílmico, assim como as interpretações daí advindas.

A ideia do ponto de vista como uma atitude mental ou inscrição de sentido é mais bem trabalhada nos escritos de Edward Branigan. Embora não remeta à discussão encaminhada por Aumont e tampouco às expressões por ele cunhadas, a estruturação dos pontos de vista no cinema para Branigan se articula em torno de cinco possibilidades: percepção, atitude, lógica de leitura, identificação e linguagem. Cada um desses itens tem um correspondente direto, que são, respectivamente, as sensações óticas, a política, a ideologia, a psicanálise e a linguística. Essa taxonomia é um útil ponto de partida porque, com exceção da primeira categoria (percepção), relacionada aos planos e aos enquadramentos que ajudam a organizar o espaço e o tempo fílmico, ${ }^{4}$ todas as outras explicitam ou desenvolvem, de certo modo, a atitude mental a que Aumont se refere. Para a discussão que pretendo encaminhar, centro as atenções nas três primeiras definições, pois elas apresentam os subsídios necessários para a construção do debate sobre pontos de vista no documentário. 
5. Do espectador para a tela; a câmera subjetiva; aquilo que o público vê, mas os personagens, não; aquilo que o personagem vê, mas o público, não; o olhar do narrador em relação aos personagens ou em relação ao espectador entre outras possibilidades.
Sobre o primeiro tópico, em vez de descrever as possibilidades de composições de olhares, ${ }^{5}$ é mais significativo apontar que a percepção sensorial apresenta formas e efeitos que, uma vez familiarizados para o espectador, ajudam-no a perceber os pontos de vistas narrativos, que podem ser atravessados por intenções políticas ou ideológicas e, posteriormente, estruturam as representações. Em outras palavras, a questão não se limita ao que se vê, mas a como se vê.

A segunda composição se refere ao ponto de vista como atitude política, cuja referência imediata é o pensamento de Sergei Eisenstein. Assim, faço menção diretamente a Eisenstein pontuando apenas que a materialização da instância política deve atentar para uma cadeia tripartite composta pelo material fílmico, pelas intenções do diretor e pela recepção do público. Nas palavras de Eisenstein (2002, p. 142):

\footnotetext{
com que métodos e meios deve o fato retratado filmicamente ser tratado a fim de que mostre, simultaneamente, não apenas o que é o fato, e a atitude do personagem em relação ao fato, mas também como o autor se relaciona com o fato, e como o autor quer que o espectador receba, sinta e reaja ao fato retratado.
}

A terceira possibilidade diz respeito a uma lógica de leitura permeada por questões ideológicas. Para isso, a percepção não deve ser vista apenas em função da experiência sensorial, mas deve considerar a cognição humana e o processamento de formas complexas. Isso permite a Branigan postular que "o entendimento do filme não acontece ad hoc, mas depende do compartilhamento de significados". ${ }^{6}$ É dentro dessa chave que a ideologia se manifesta como uma lógica de leitura, que exige do espectador abandonar uma suposta zona de neutralidade.

original: "My contention is that our understanding of film is not ad hoc but dependes on a shared set of rules or assumptions (= meaning)".

\section{O ponto de vista no documentário}

A partir das considerações de Aumont e Branigan, vê-se que a discussão sobre os pontos de vista no cinema é ampla e pode apontar vários caminhos. Há uma diversidade de "atores" 
7. Há ainda uma série de outras discussões sobre as constituições dos pontos de vista no cinema em que não me deterei, tendo em vista

que as ponderações de Aumont

e Branigan já me fornecem os subsídios necessários. Mesmo assim não se pode deixar de apontar que

autores como Jean Mitry, André

Bazin, Noel Burch e Nick Browne também se detiveram nesse assunto.

A lista de Branigan ainda inclui

Wayne Booth, Norman Friedman,

Dudley Andrew e Bruce Kawin.

8. Esse aspecto se torna evidente no pensamento de Branigan, cujos

primeiros apontamentos sobre os pontos de vista no cinema se deram nos anos 70, momento em que semiologia, linguística, psicanálise, assim como as interferências dos "aparelhos ideológicos do Estado", estavam no olho do furacão dos circuitos acadêmicos.

9. GOMES, 1984, p. 70. Não me deterei em uma análise do filme Vigo, mas sim em suas conclusões, uma vez que o trabalho de Paulo Emílio Salles Gomes já cumpre essa tarefa, assim como as discussões encaminhadas por Michael Chanan (2007, p. 101-103), a partir também do trabalho de Salles Gomes. envolvidos - espectador, narrador, personagem, cineasta assim como inúmeros encaminhamentos - percepções sensoriais via linguagem cinematográfica, a questão da narrativa, a atitude política, o olhar ideológico e as heterogêneas materializações da representação. Essa discussão se estrutura em função do tempo e do espaço onde foi pensada ${ }^{7}$ e inevitavelmente reflete a roupagem do debate acadêmico de sua época, ${ }^{8}$ sinalizando que o ponto de vista (desta vez como opinião e visão de mundo, e não como o conceito aqui articulado) determina o objeto, e o "objeto" em foco é exatamente a ideia de ponto de vista no cinema. Esse jogo ambíguo evidencia que, em vez de se ater a uma única definição, numa tentativa de domesticar o debate, é mais relevante atentar para as inúmeras modulações da noção de ponto de vista.

Se, por um lado, as definições de pontos de vista não estabelecem uma separação entre os formatos e gêneros cinematográficos, centro as atenções a partir de agora na apreensão dos pontos de vista tendo o documentário como norte desse percurso. Porém não pretendo, com esse encaminhamento, estabelecer cisões entre o campo documental e o "restante" da produção audiovisual, pois seria anacrônico não somente em relação aos postulados de Aumont e Branigan, que não estabelecem separações, mas também em relação à discussão em torno do documentário, que há décadas se esforça para superar possíveis dicotomias surgidas entre o documentário e a ficção. A intenção aqui é delimitar o campo de atuação para que se evitem as armadilhas das generalizações, possíveis em áreas extremamente amplas como os estudos de cinema.

Dessa forma, a noção de ponto de vista documentado, apresentado por Jean Vigo, em virtude da realização do documentário A propósito de Nice (Jean Vigo, 1930), torna-se particularmente importante. Esse ponto de vista seria, segundo Vigo, uma espécie de fusão entre a abordagem de demandas sociais e os impulsos criativos do diretor, conduzindo-o ao que Paulo Emílio Sales Gomes denomina de "documentário social". . Embora o plano social seja o foco do ponto de vista documentado, não se pode desprezar o fato de que a "dimensão pessoal" (BARNOUW, 1993, p. 76) seja um aspecto-chave para a sua constituição. Em seu 
10. A partir desse propósito, Gomes (1984, p. 76) defenderá a ideia de que "o ponto de vista documentado revela-se como que uma ressurreição do cine-olho".

11. Essa ideia pode parecer hoje ponto pacífico, mas não se pode esquecer que o filme de Vigo veio à tona num momento de efervescência das vanguardas artísticas, que, mesmo "antenadas" com o mundo histórico à sua volta, pareciam concentrar as atenções na experimentação ou na subversão das formas já consagradas.

12. No original: "these pieces were predicated on the necessity of offering corrective visions, alternatives to the dominant historical discourse which had scanted the struggles of labor, women, the underclasses, and the marginalized. All too frequently, however, the interest in the visual document - interview footage intercut with archival material outpaced the historian's obligation to interrogate rather than simply serve up the visible evidence". estudo sobre Jean Vigo, Gomes (1984, p. 74) ressalta que o cineasta francês tinha consciência desse duplo posicionamento, embora preferisse marcar seu lugar de fala a partir da crítica social, pois essa estratégia seria uma forma de "livrar-se da técnica pela técnica e de sua sutileza". Essa intenção não se restringia, entretanto, apenas à esfera da realização do ponto de vista documentado, mas tinha também o propósito de "envolver o público" (GOMES, 1984, p. 74), encaminhá-lo à reflexão. ${ }^{10}$ Para tanto, o método considera, nas palavras de Vigo, que "a câmera será apontada para o que deve ser considerado como um documento e que será interpretado, na montagem, enquanto documento" (apud GOMES, 1984, p. 75).

Essa primeira aproximação em relação ao ponto de vista no documentário se dá, portanto, por meio de um exercício empírico de realização cujo objetivo é a crítica a um determinado escopo social. Em outras palavras, A propósito de Nice devolveu à sociedade uma espécie de "teoria", em que se ressaltou a importância do comprometimento do documentário com o seu contexto sóciohistórico. ${ }^{11}$ As décadas posteriores confirmariam esse pressuposto como uma marca indissociável do cinema documental: o enfrentamento de temas espinhosos ou a abordagem das agruras do mundo. Como chama a atenção Renov (1993, p. 26):

\begin{abstract}
essas peças [documentários] pressupõem a necessidade de oferecer visões corretivas, alternativas para o discurso dominante que restringem as lutas históricas dos trabalhadores, das mulheres, das classes subalternas e dos marginalizados. Com demasiada frequência, contudo, o interesse no documento visual - sequências de entrevistas intercaladas com materiais de arquivo ultrapassou a obrigação do historiador para interrogar, em vez de simplesmente servir a evidência visível. ${ }^{12}$
\end{abstract}

A ideia de um ponto de vista documentado trouxe à baila pela primeira vez a relevância de atentar para as searas subjetivas e sociais, produzindo um resultado que mescla a experimentação artística com a crítica social. O que deve ser extraído do postulado de Vigo é a articulação entre as esferas da realização, que compreende desde as intenções do diretor ao produto final, atenta não somente aos 
13. Para detalhes sobre essas variadas possibilidades combinatórias, ver NINEY, 2009, p. 87-89.

14. NINEY, 2000, p. 65. No original: “[...] la dialectique nécessaire à produire [...] du sens, un plus de réalité et de possible, à construire un tout qui soit plus que la somme de ses parties, une oeuvre significative à la hauteur d'un monde en devenir". seus propósitos pessoais mas também à circulação do filme entre o público com o objetivo de propor um ponto de vista. Esse arranjo entre intenções e materializações pode soar como ponto pacífico, mas a sua suposta obviedade apresenta um aspecto importante para o estudo aqui empreendido; ou seja, quais elementos são utilizados e como se dá a passagem da esfera do discurso para a materialidade fílmica. Em outras palavras, as opções discursivas e de linguagem que moldam os pontos de vista da produção de documentários.

Os diversos vetores que compõem os pontos de vista no cinema vão ao encontro de um "senso de orientação" (NINEY, 2000, p. 65), em que os pontos de vista não existem por si só ou previamente, mas se articulam em torno do seu contexto e de suas condições de produção. As questões relativas à narrativa e à representação, anteriormente apresentadas como estruturantes dos pontos de vista, estão relacionadas a uma cadeia formada por cineasta, personagem e espectador, que apresenta inúmeras combinações entre essas partes na composição dos pontos de vista. ${ }^{13}$ Uma vez que os discursos são múltiplos e polivalentes e estão inseridos num contexto assimétrico, esses três elementos ajudam a construir uma “dialética necessária para produzir sentido, [...] para construir um todo que seja mais que a soma de suas partes, uma obra significativa à altura de um mundo por vir". ${ }^{14}$

Se a discussão em torno do ponto de vista no documentário pode se iniciar com o ponto de vista documentado que se configura como um senso de orientação, deve-se agora discutir as possibilidades interpretativas do documentário, pois pensar o ponto de vista é pensar a interpretação (a atitude mental ou a inscrição de sentido, segundo Aumont). Para tanto, duas leituras se revelam úteis: a mediação em detrimento da transparência, fornecida pelas imagens e sons cuja aposta é na dúvida e na ambiguidade e, atrelado a esse aspecto, a leitura por deslocamentos, quando as nossas experiências sociais e pessoais permitem extrair interpretações que não se apresentam nitidamente na tela (CORNER; RICHARDSON, 1986). São leituras que, quando justapostas, devolvem para o público outros modos de ver e mostrar, em que diferentes representações verbais e visuais se organizam em torno de uma suspeita que, por sua vez, 
15. Comolli formula a questão de modo semelhante. Para ele, o multifacetado regime de imagens

à nossa disposição nos leva a

acreditar nas imagens, mas, ao mesmo tempo, a desacreditá-las.

Nas palavras do autor: "Com

a dissipação da realidade do mundo, que resulta da ascensão do espetáculo e simultaneamente a produz, essas realidades perdem o poder sobre nós $[\ldots]$. Ora, a questão

do cinema continua: como crer nelas mesmo assim. Como fazer funcionar essa denegação que forja a relação do espectador com o espetáculo e pela qual $[\ldots]$ começa o movimento de adesão, de uma crença?" (COMOLLI, 2008, p. 222, grifo do autor). impulsiona a discussão. ${ }^{15}$ Elas revelam as diferenças entre uma realidade preexistente e possíveis descompassos da representação.

De fato, essas ponderações funcionam mais como o ponto de partida que como a palavra final a respeito das interpretações fornecidas pelos documentários. Arriscaria a afirmar, inclusive, que elas se materializam mais como o desejo de seus autores em relação às consequências interpretativas de uma peça documental que de fato se confirmam como uma constante "tendência". Embora parcial, essa dupla possibilidade aponta diretamente para a definição de ponto de vista proposta por Aumont (1985, p. 134), que "diferente do modelo pictórico, o ponto de vista defini-se, no cinema, como uma série ordenada e mediada". Essa "ordenação" da interpretação opera em dois níveis: o ponto de vista toma o plano (ou a sequência de planos) como ponto de partida para chegar a uma interpretação, que extrapola o campo fílmico num movimento que se dá entre o interior (espaço fílmico) e o exterior (a interpretação). É nesse momento que se pode definir o ponto de vista no documentário como uma interpretação que organiza um senso de orientação a partir dos aspectos sensoriais (fornecidos via imagem e som) e das mediações de demandas contextuais (a política, a ideologia, o social). Para o documentarista, a organização desse duplo vetor pode ser consciente ou inconsciente, pois cada plano exige um grau de envolvimento que pode ser previamente controlado ou não. Porém, imagem e narrativa, quando articuladas pela montagem, tornam-se duas importantes ferramentas para a expressão de um ponto de vista, sendo ele, portanto, sempre uma questão de recorte. Em resumo, o ponto de vista é um espaço de materialização de uma visão que um determinado documentário põe à nossa disposição.

Mas essa definição não pode servir para polarizar o campo documental e o restante da produção cinematográfica, mas sim apontar um caminho, uma senda, uma chave para pensar uma possível formulação do que caracteriza o ponto de vista no documentário, ainda que essa definição possa ser útil para pensar, por que não, a ficção. Meu intuito foi o de construir um mosaico de referências atento mais à interlocução que à oposição. Logo, não se trata de fixar fronteiras, mas de sugeri-las, apontá-las, apresentá-las, ainda que elas possam ser porosas e polifônicas. 


\section{Referências}

AUMONT, J. O olho interminável [cinema e pintura]. São Paulo: Cosac Naify, 2004.

. "O ponto de vista". In: GAEDA, E. (Org.). Estéticas

do cinema. Lisboa: Dom Quixote, 1985.

AUMONT, J.; MARIE, M. Dicionário teórico e crítico de cinema. Campinas: Papirus, 2003.

BARNOUW, E. Documentary: a history of the non-fiction film. Oxford: Oxford University Press, 1993.

BAZIN, A. O cinema: ensaios. São Paulo: Brasiliense, 1991.

BRANIGAN, E. Narrative comprehension and film. New York: Routledge, 1992.

Point of view in the cinema. New York: Mouton, 1984.

CHANAN, M. The politics of documentary. Londres: British Film Institute, 2007.

COMOLLI, J-L. Ver e poder - a inocência perdida. Cinema, televisão, ficção, documentário. Belo Horizonte: UFMG, 2008.

CORNER, J.; RICHARDSON, K. "Documentary meanings and the discourse of interpretation". In: CORNER, J. (Org.). Documentary and the mass media. Londres: Edward Arnold, 1986.

EISENSTEIN, S. A forma do filme. Rio de Janeiro: Jorge Zahar, 2002.

GAUDREAULT, A.; JOST, F. A narrativa cinematográfica. Brasília: UnB, 2009.

GENETTE, G. Discurso da narrativa. Lisboa: Vega, 1995.

GOMES, P. E. S. Jean Vigo. São Paulo: Paz e Terra, 1984.

JOST, F. El ojo-cámara: entre film y novela. Buenos Aires: Catálogos, 2002.

NINEY, F. Le documentaire et seux faux semblant. Paris: Klincksieck, 2009. 
L'épreuve du réel à l'écran: essai sur le principe de réalité documentaire. Paris; Bruxelas: De Boeck, 2000.

RENOV, M. "Toward a poetics of documentary". In: RENOV, M. (Org.). Theorizing documentary. Nova York: Routledge, 1993. 